This item was submitted to Loughborough's Research Repository by the author.

Items in Figshare are protected by copyright, with all rights reserved, unless otherwise indicated.

\title{
Polymer optical waveguide fabrication using laser ablation
}

PLEASE CITE THE PUBLISHED VERSION

http://dx.doi.org/10.1109/EPTC.2009.5416408

PUBLISHER

(c) IEEE

VERSION

AM (Accepted Manuscript)

LICENCE

CC BY-NC-ND 4.0

REPOSITORY RECORD

Zakariyah, Shefiu S., Paul P. Conway, David A. Hutt, David Selviah, Kai Wang, Hadi Baghsiahi, Jeremy Rygate, Jonathan Calver, and Witold Kandulski. 2019. "Polymer Optical Waveguide Fabrication Using Laser Ablation". figshare. https://hdl.handle.net/2134/9065. 
This item was submitted to Loughborough's Institutional Repository (https://dspace.lboro.ac.uk/) by the author and is made available under the following Creative Commons Licence conditions.

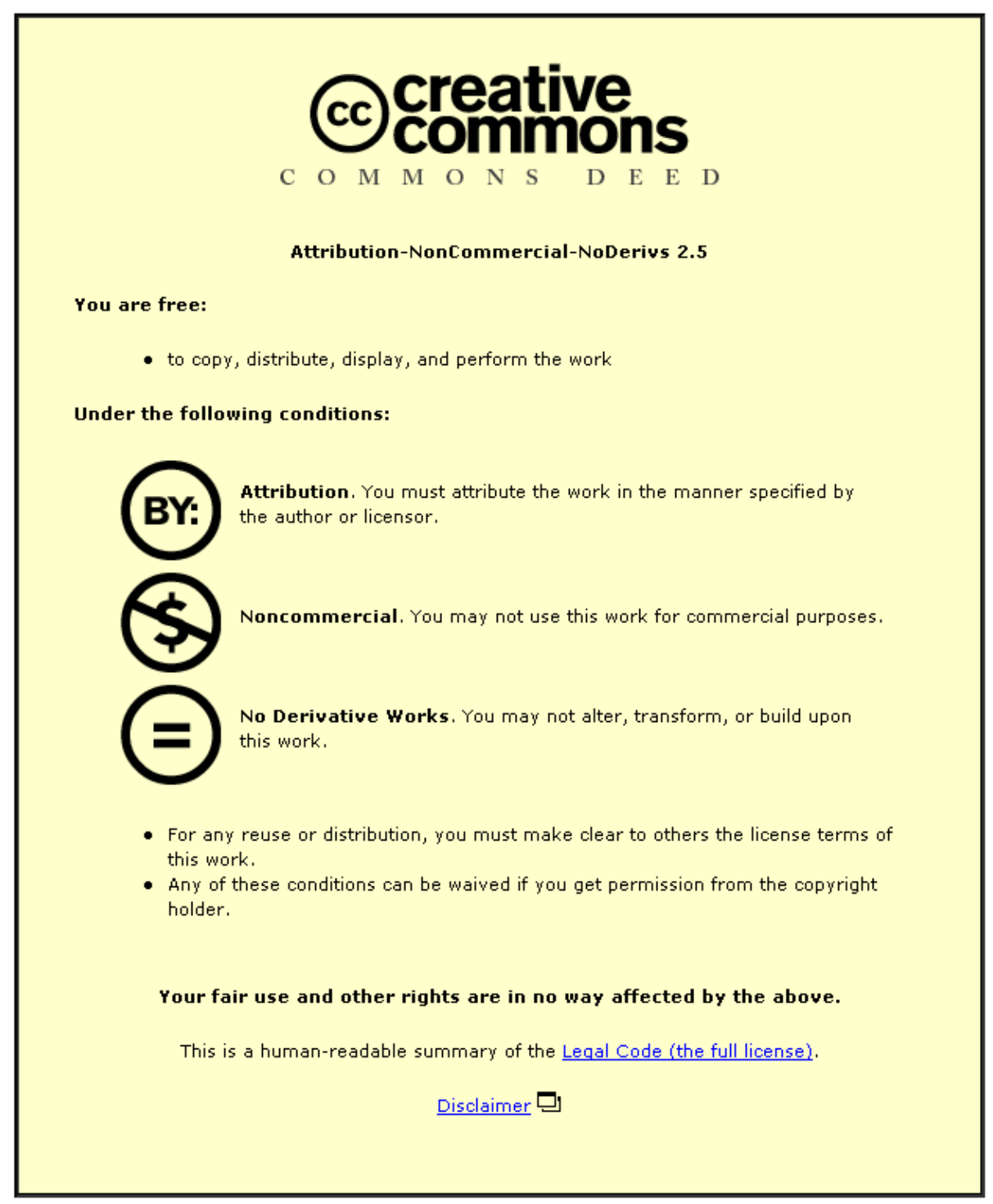

For the full text of this licence, please go to: http://creativecommons.org/licenses/by-nc-nd/2.5/ 


\title{
Polymer Optical Waveguide Fabrication Using Laser Ablation
}

\author{
$\uparrow$ Shefiu S. Zakariyah, $\uparrow$ Paul P. Conway, $†$ David A. Hutt, \#David Selviah, \#Kai Wang \\ \#Hadi Baghsiahi *Jeremy Rygate, *Jonathan Calver, *Witold Kandulski \\ $\dagger$ Wolfson School of Mechanical and Manufacturing Engineering \\ Loughborough University, Loughborough, Leicestershire, LE11 3TU, UK. \\ \#Department of Electronic and Electrical Engineering \\ University College London (UCL), Torrington Place7, London, WC1E 7JE, UK \\ *Stevenage Circuits Limited, Caxton Way, Stevenage, Hertfordshire SG1 2DF, UK \\ Email: S.S.Zakariyah@lboro.ac.uk, shefiuz@theiet.org
}

\begin{abstract}
Due to their inherent bandwidth capacity, optical interconnects are replacing copper as bottlenecks begin to appear within the various interconnect levels of electronics systems. Current optical interconnect solutions found in industry are based upon optical fibres and are capable of providing a suitable platform for inter-board applications. However, to allow high speed interconnects between components and within systems, optically enabled printed circuit boards containing waveguides are essential. One way in which this can be accomplished is through the integration of polymer optical waveguides into traditional printed circuit boards (PCBs). There are a number of routes to accomplish this including photolithography and laser direct imaging, however, this paper explores laser ablation using UV and IR sources namely: $248 \mathrm{~nm}$ Excimer, $355 \mathrm{~nm}$ UV Nd:YAG and $10.6 \mu \mathrm{m} \mathrm{CO}_{2}$, to form waveguide structures in optical polymer materials. The paper presents the process route and initial results of trials conducted to fabricate waveguides and indicate the variation in the structures formed by the different lasers. The demonstration of the use of these three lasers for optical waveguide fabrication may provide a route to the rapid deployment of this technology into the PCB industry through the use of existing infrastructure.
\end{abstract}

\section{Introduction}

Interconnection using optical principles for long-haul telecommunication is now an established technology with optical fibres (or waveguides) used as light pipes in conveying signals. In recent years, research has inclined towards adapting the same principles at board level, driven by requirements for higher data transfer rate, higher density interconnection and smaller packages, which has proven impracticable with conventional electrical connections. For this technology, polymer waveguides are favoured, not only because of their ease of fabrication and integration with other optoelectronic devices, but also their compatibility with PCB manufacturing processes. Photolithography, direct laser writing, hot embossing and reactive ion etching (RIE) are suitable for preparing optical waveguides and being reportedly used [1-2].

Laser micromachining has opened up new chapters in microtechnology in MEMS and in other fields such as the biomedical industry. Lasers have been used extensively in PCB manufacturing for areas such as microvia drilling and soldering to mention but a few, offering both efficiency and cost-effectiveness. The presence of this infrastructure within PCB companies makes the fabrication of optical waveguides by laser ablation an attractive option. In addition, laser ablation can enable the definition of integrated mirrors that are required for coupling light in and out of optical waveguides.

Excimer lasers, typically at $193 \mathrm{~nm}$ and $248 \mathrm{~nm}$ wavelength, have been widely used to machine polymer materials including those used for the fabrication of optical waveguides [3-7], but less attention has been given to other close-match competitors such as UV Nd:YAG lasers. With the Excimer laser, ablation of polymers is thought to be largely photochemical (athermal) due to absorption of the short UV pulses (typically, $10-35 \mathrm{~ns}$ in length) leading to relatively clean ablation with little thermal damage of the surrounding material. However, its low speed and running cost, coupled with the use of toxic gases, such as fluorine $\left(\mathrm{F}_{2}\right)$, are some of the reasons for its comparatively low acceptance in the PCB industry.

On the other hand, UV Nd:YAG (frequency tripled) lasers are widely used in industry and could also be adapted for this application. UV Nd:YAG laser ablation of PCB materials stands as a good competitor to Excimer, but its use as a tool for optical polymer waveguides has only been explored, to the best of our knowledge, by Van Steenberge et al [8]. Furthermore, despite the fact that $\mathrm{CO}_{2}$ lasers are commonly used in PCB manufacture with relatively low cost and reasonably high processing speed, there does not appear to have been any reported work on optical waveguide fabrication using this IR laser source. This may be as a result of the fact that the $\mathrm{CO}_{2}$ laser-material interaction is mainly photothermal, leading to a relatively high Heat Affected Zone (HAZ), compared to the minimal HAZ characteristics of Excimer (and, to some degree, UV Nd:YAG) laser ablation, even though there is no evidence to suggest the negative effect of this on the propagation loss obtained from the resulting waveguides.

The aim of this study is to investigate the fabrication of optical waveguides using these three laser sources (Excimer, UV Nd:YAG \& $\mathrm{CO}_{2}$ ). The successful use of these three lasers, operating in the UV \& IR-regions of the electromagnetic spectrum would indicate that laser ablation of optical polymer waveguides is not limited to a particular wavelength or group of wavelengths though one might have some advantage(s) over the other. In addition, this study can facilitate the deployment of this new technology to its targeted industry since the current laser set-ups for microvia drilling could also be used for optical-PCB manufacture. 


\section{Optical Polymer Materials}

The two main polymers of choice in this research were Truemode (EXX formulation) and polysiloxane (OE4140 / OE4141) manufactured by Exxelis Ltd and Dow Corning respectively. Both materials are UV cure formulations principally designed to be patterned by photolithography [9 11] .

Excimer laser ablation of waveguides in Truemode material has been reported by researchers at TFCG Microsystem, Ghent [12, 13], but not in Polysiloxane photopolmer. Furthermore, no literature appears to be available on the use of $\mathrm{CO}_{2}$ laser ablation in patterning optical structures in either of these materials, thus forming the basis of the authors' interest.

\section{Optical polymer waveguide fabrication}

The stages or processes involved in laser ablating a polymer waveguide as employed in this research are schematically shown in Fig. 1. They are: -

1. Deposition of optical polymer on FR4 laminates to form both lower cladding and core layers. This is usually achieved by spin coating. There is no principle as to how thick the cladding layer should be but it is generally expected to be of a reasonable thickness, in most cases, greater than the core layer. The core layer thickness should be the same as the final height of the waveguide.

2. Laser ablation of grooves in the core layer, to leave a ridge of polymer in-between which represents the waveguide channel. Typical dimensions are $50 \mu \mathrm{m} x$ $50 \mu \mathrm{m}, 50 \mu \mathrm{m} \times 70 \mu \mathrm{m}$ and $70 \mu \mathrm{m} \times 70 \mu \mathrm{m}$ for multimode waveguides, but other dimensions such as $40 \mu \mathrm{m} \times 45 \mu \mathrm{m}$ [14] and $35 \mu \mathrm{m}$ x $35 \mu \mathrm{m}$ [15] have been reported. The material removal process (ablation) is continued to penetrate beyond the core layer in to the lower cladding to ensure that the light signal is completely contained in the core by Total Internal Reflection (TIR).

3. The last stage is to deposit another layer of cladding known as the upper cladding. This is to ensure that TIR is achieved. For measuring the transmission of the waveguides, this stage is not essential because the surrounding air is of lower refractive index and can thus serve as an upper cladding layer, however without protection, the core/air interface could become contaminated or damaged, leading to optical losses.

In this work, samples of polysiloxane lower cladding (OE4140) and core (OE4141) on FR4 were supplied directly by Dow Corning ready for laser ablation. Samples of Truemode on FR4 were prepared by spin coating the Truemode at $300 \mathrm{rpm}$ for 30 seconds for the cladding layer and at $400 \mathrm{rpm}$ for the core layer in order to obtain $70 \mu \mathrm{m}$ and $50 \mu \mathrm{m}$ thick layers respectively. After each spin coating process, the layers were cured by exposing them to UV for the required time in a light box in an oxygen-free nitrogen atmosphere. Following this, the sample was placed in an oven to bake the optical layer in order to complete the cure process. This was performed at $\sim 80^{\circ} \mathrm{C}$ for one hour for the EXX formulation of Truemode.
Samples of Truemode and polysiloxane were ablated using the three different laser systems as discussed in the following sections. Due to possible debris deposition on the ablated structures and other forms of contamination, samples required cleaning before depositing the upper cladding. To do this, the samples were rinsed in either water, methanol or iso-propanol and in the case of serious contamination, sonication was also required. The upper cladding was applied to the structure by spin coating of the liquid formulation followed by UV cure and bake.

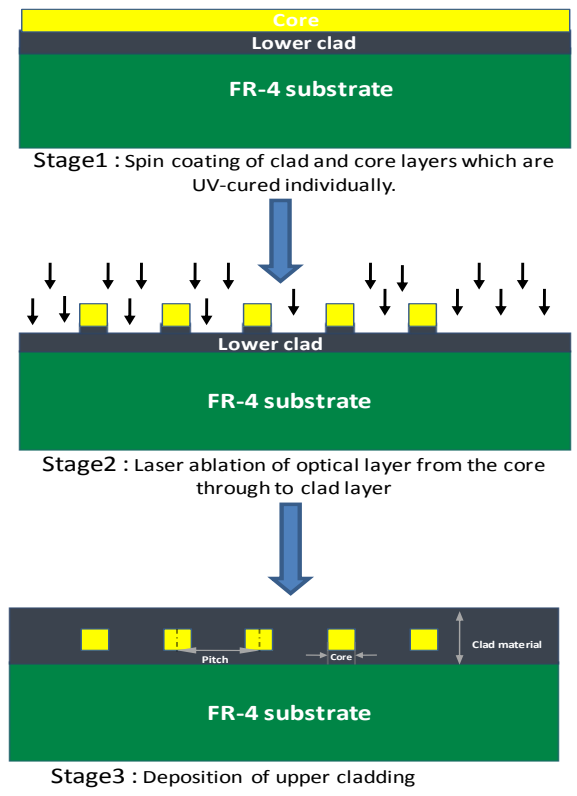

Figure 1: Schematic diagram of the three major stages in the fabrication of optical waveguides by laser ablation: (1) deposition of optical polymer (e.g. Truemode) on FR4 substrate to form lower cladding and core layers; (2) removal of materials on both sides of the core using laser ablation; and (3) coverage with an upper cladding layer.

\section{Sample Preparation and Measurement}

For the purpose(s) of analysis and/or measurement, the ablated samples were sectioned using a Buehler ISOMET low speed saw and then mounted in a potting compound. Samples were polished using a series of abrasives down to $1 \mu \mathrm{m}$ diamond paste. In situations where mounting was not required, samples were manually held and ground in sequence over four different $\mathrm{SiC}$ papers of 220, 400, 600 and 800 grit.

To demonstrate continuous waveguide paths before any propagation loss measurements were carried out, a SmartScope ${ }^{\circledR}$ Flash $^{\mathrm{TM}} 200$ system was employed. In this case, the backlight feature of the system was used to shine white light with a spot size dimension similar to the waveguide cross-section into one end of the waveguide. Once this was established, then the waveguide was ready for propagation loss assessment using an $850 \mathrm{~nm}$ VCSEL connected via a 50 micron core multi mode step index fibre.

\section{Experimental Results and Discussion}

\section{(A) $\mathrm{CO}_{2}$ Laser Ablation of Optical Waveguides}

The $\mathrm{CO}_{2}$ laser used was an air-cooled SYNRAD series-48 IR laser source with a fundamental wavelength of $10.6 \mu \mathrm{m}$. WinMark Pro® software was used to control the experimental 
parameters such as laser power and speed of scanning. The laser operates in the continuous wave $(\mathrm{CW})$ mode with Gaussian $\mathrm{TEM}_{00}$ beam profile and a maximum power of 10 Watts with output specified as a percentage of maximum power. The laser system was principally designed for engraving, marking and simple cutting.

The wavelength of the $\mathrm{CO}_{2}$ laser in the mid-IR region leads to heat generation making the laser a good source for thermal or heat-related applications. Fig. 2a is a schematic diagram of the Gaussian beam intensity profile of the experimental setup which was used without any further beam shaping to ablate the sample. The beam spot size was $300 \mu \mathrm{m}$ in diameter and was scanned across the sample. As result of this beam intensity profile, samples ablated had curved profiles (Fig. 2b).

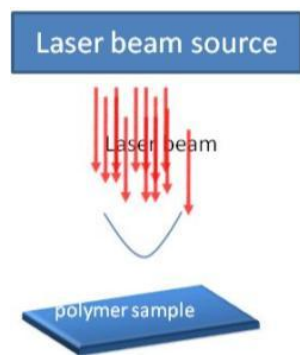

(a)

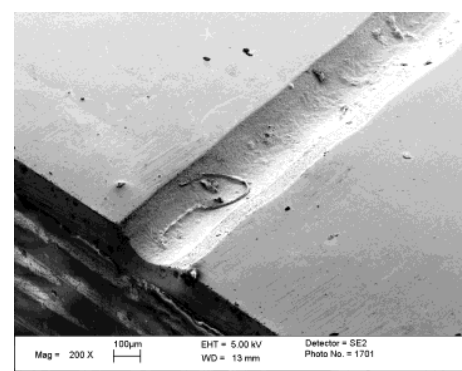

(b)
Figure 2: (a) Schematic diagram of the Gaussian beam profile of the $\mathrm{CO}_{2}$ laser system setup used for the fabrication of optical polymer waveguides (b) An SEM image of a groove machined in Truemode showing the effect of the Gaussian beam profile of the $\mathrm{CO}_{2}$ laser.

The use of the $\mathrm{CO}_{2}$ laser for polymer waveguide fabrication is unprecedented, as previously mentioned, necessitating system optimization due to the photothermal effects between the beam and the polymer. Laser - material interaction and/or system characterization was carried out, centred on changing power and scanning speed parameters. Ablating at varying powers of $1-9$ Watts and varying the speed between $100 \mathrm{~mm} / \mathrm{s}$ to $700 \mathrm{~mm} / \mathrm{s}$ was investigated. It was found that a change in any of the two main variable parameters affected the visual quality of the ablated channels. For instance, increasing the speed of scanning from $150 \mathrm{~mm} / \mathrm{s}$ to $400 \mathrm{~mm} / \mathrm{s}$ at a fixed output power of 5 Watt drastically improved the quality of ablation on the Polysiloxane material (Fig. 3). It was noted that although the beam spot was $300 \mu \mathrm{m}$ in diameter, due to the Gaussian beam intensity profile and ablation threshold of the polymer, the width of the machined features was smaller than the beam width. This could be seen in the lines shown in Fig. 3, which became progressively narrower as the laser scan speed was increased. It was also observed that at 1 Watt and 2 Watt, no ablation occurred, however, when powers of 3 to 5 Watts were used, waveguides were achieved using scanning speeds of $100 \mathrm{~mm} / \mathrm{s}$. Overall, it was found that there were some sets of combinations of power and speed that led to satisfactory ablation. Fig. 4 shows four adjacent waveguides of $60 \mu \mathrm{m}$ by $30 \mu \mathrm{m}$ with a pitch of 200 $\mu \mathrm{m}$. The waveguides had a trapezoidal shape due to the curved ablation profile shown earlier. At present it is not clear what effect this shape has on the propagation losses. Various numbers of adjacent waveguides, up to nine, were also investigated, with the intention of understanding whether the optical density (i.e. concentration of the waveguides) would have an effect on the propagation loss, especially, as in the case of $\mathrm{CO}_{2}$, where the process is photothermally dominated.

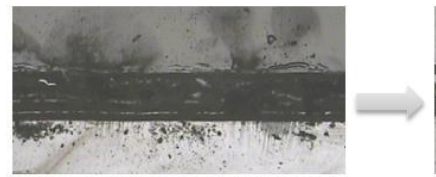

(a) Power: 5W; Speed : $150 \mathrm{~mm} / \mathrm{s}$ )

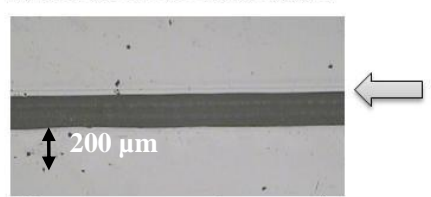

(d) Power: $5 \mathrm{~W}$; Speed : $400 \mathrm{~mm} / \mathrm{s}$ (c) Power: $5 \mathrm{~W}$; Speed : $350 \mathrm{~mm} / \mathrm{s}$

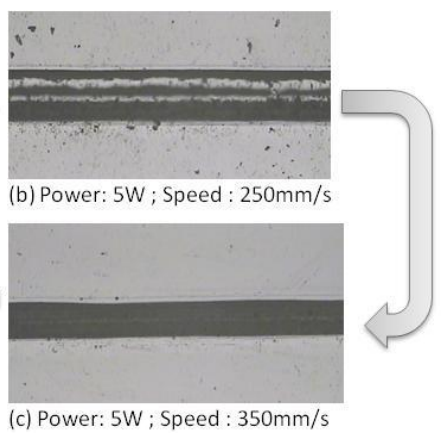

Figure 3: Optical microscope images showing the effect of scanning speed between $150 \mathrm{~mm} / \mathrm{s}$ to $400 \mathrm{~mm} / \mathrm{s}$ at a fixed power of 5 Watt on Polysiloxane (OE4140 \& OE 4141)

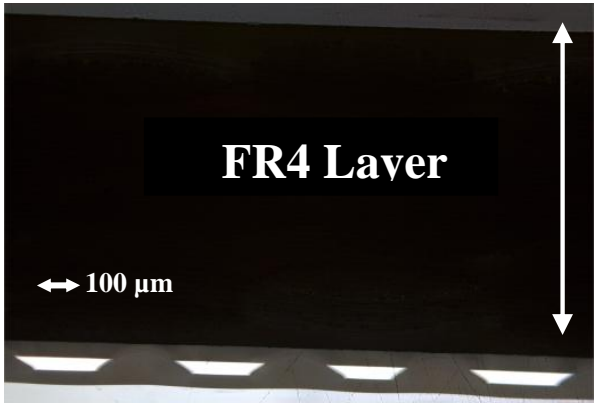

Figure 4: An image of four adjacent waveguides fabricated using the $\mathrm{CO}_{2}$ laser in Truemode acrylate photopolymer. The image is shown with the FR4 substrate towards the top of the picture.

\section{(B) UV Nd:YAG Laser Ablation of Optical Waveguides}

The UV Nd:YAG laser used in this project was a diodepumped frequency-tripled UV Nd:YAG laser system manufactured by Electro Scientific Industries (ESI), model $5200 \mathrm{UV} \mu \mathrm{Via}$ Drill, which operates at a wavelength of 355 $\mathrm{nm}$. The beam profile was Gaussian $\left(\mathrm{TEM}_{00}\right)$ having pulse repetition frequency of up to $20 \mathrm{kHz}$ with $60 \mathrm{~ns}$ pulselength. The system was configured with a fixed beam size of $25 \mu \mathrm{m}$ diameter, primarily designed for drilling holes in PCBs. Therefore, to machine a groove greater than $25 \mu \mathrm{m}$ wide required several passes of the beam across the sample to be made and overlapped.

The narrow beam led to an ablated shape (Fig. 5) that was not as curved as that obtained on the $\mathrm{CO}_{2}$ laser making the waveguide profile obtained on this system similar to that expected on an Excimer laser or any laser with a beam homogeniser. 


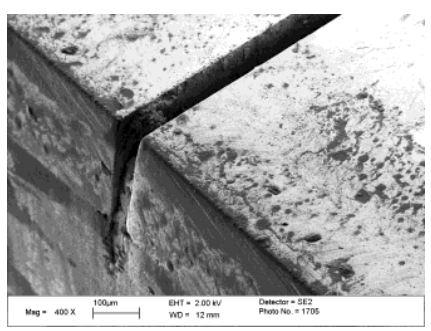

(a)

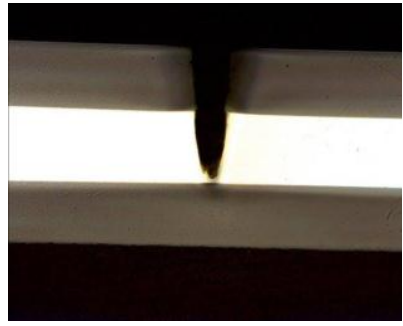

(b)
Figure 5: Grooves machined in Truemode polymer using UV

Nd:YAG laser. (a) SEM view and (b) Side view optical microscope image.

From the available literature it is still not clear whether laser ablation at $355 \mathrm{~nm}$, is purely photothermal or photochemical, or a combination of both. The UV Nd:YAG ablation is governed by certain controllable experimental parameters which formed the centre of the laser system characterization and waveguide fabrication trials. The effects of the velocity of the translational stage, pulse frequency, laser power and number of laser passes on the depth of ablation were examined. Figure 6 shows some examples of the results obtained. Reports have shown different behaviours with regards to changes in pulse repetition rate (frequency, PRR), laser type (UV wavelength) and absorption of the materials [16 - 18]. To investigate the relevance of pulse frequency (PRR), samples were ablated with fixed laser power, translation stage speed and number of passes (i.e. repeat machining on the same area / line), while the frequency of the laser was increased at intervals of $5 \mathrm{kHz}$ between $5 \mathrm{kHz}$ and $20 \mathrm{kHz}$. Fig 6a plots the ablation depth as a function of frequency at fixed power and stage speed. Examination of the graph showed that there are two distinctive regions, both of which require different interpretations. This curve is similar, but converse to that reported for Excimer laser ablation of ABS (Acrylonitrile butadiene styrene) polymer, in which the graph showed a maximum rather than a minimum [18]. The two regions are thought to correspond to different ablation mechanisms: in the first region, an increase in frequency led to a reduction in ablation as incident pulses which were in excess of those required to cause ablation of the polymer were absorbed by the ablated material and surroundings and thus converted to heat energy. This increased the temperature of the ablation region but not enough to result in photothermal ablation [16]. In the second region, increasing the PRR eventually resulted in the photothermal threshold being reached making ablation at this stage not only photochemical but also photothermal, thus increasing the ablation rate. For some laser-material combinations, frequency has been found to have no direct effect on the quantity of ablation in certain frequency ranges, as some authors have reported [17] for Excimer laser ablation of polymers with high absorption coefficients, namely: polycarbonate (PC), Poly Ethylene Terephthalate (PET), Polyimide (PI) and polystyrene (PS). The same author found out that, with low absorption coefficient polymer, namely, PMM, increase in frequency increased the ablation rate, this latter behaviour with PMMA was attributed to heat accumulation. It can therefore be said that, the frequency dependence is likely to be determined by particular combinations of other parameters as well.
Fig. $6 \mathrm{~b}$ is a plot showing the effect of stage speed on the depth of ablation. In this set of experiments, all factors were kept constant with the exception of the velocity of the translation stage, which was increased at intervals of $5 \mathrm{~mm} / \mathrm{s}$ between 5 and $20 \mathrm{~mm} / \mathrm{s}$. It could be observed from this figure that the speed of the translation stage played a major role in the amount of material removed, which is inversely proportional to the depth of ablation. In other words, more material was removed at low speed due to more pulses reaching the material at this instance. Following this study, the authors favour the principle that ablation in these materials at $355 \mathrm{~nm}$ is a photochemical - photothermal mechanism acting in different degrees depending on the parameter combination.

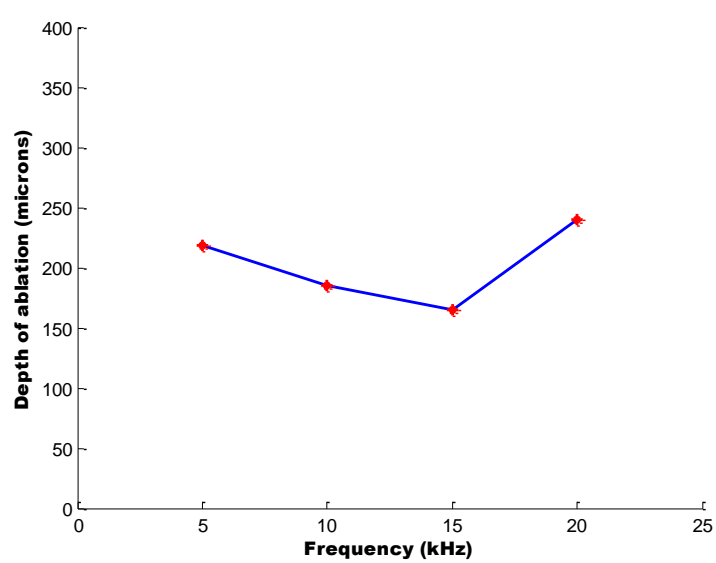

(a)

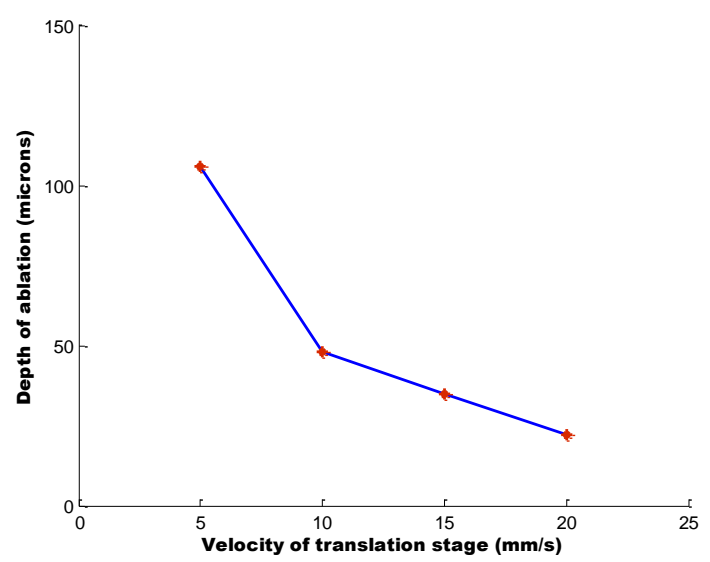

(b)

Figure 6: UV Nd:YAG laser system characterisation using

Truemode optical polymer showing: (a) Graphical representation of the effect of frequency on depth of ablation at constant power of $0.1 \mathrm{Watt}$, translational stage speed of 5 $\mathrm{mm} / \mathrm{s}$ and 4 laser passes, (b) Graphical representation of the effect of stage speed on the depth of ablation at 0.1 Watt and 5 $\mathrm{kHz}$ with 2 laser passes.

A single multimode waveguide of about $45 \mu \mathrm{m} \times 45 \mu \mathrm{m}$ and $60 \mathrm{~mm}$ long was fabricated by ablating a $\sim 200 \mu \mathrm{m}$ wide groove on each side of the structure (Fig. 7). Since the laser has a $25 \mu \mathrm{m}$ fixed beam size, eight beam passes were made, each overlapped by $1 \mu \mathrm{m}$. A $25 \mu \mathrm{m}$ wide groove could have 
been used here, however the choice of $200 \mu \mathrm{m}$ in this case was to allow for easy alignment on the loss measuring system.

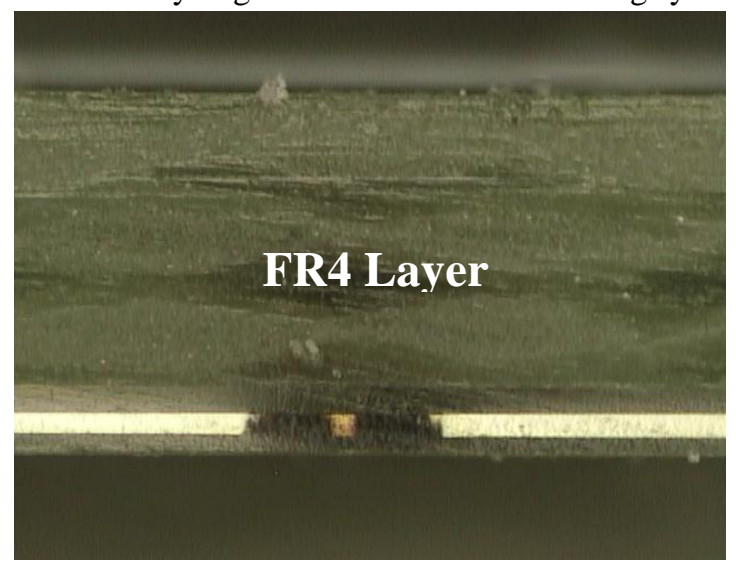

Figure 7: Waveguide of $45 \mu \mathrm{m}$ x $45 \mu \mathrm{m}$ made on Truemode optical polymer using the 5200 model UV Nd:YAG laser

system. Image obtained on OGP Flash200 Optical Microscope.

In order to improve the waveguide profile to remove the tapering effect of the Gaussian beam profile, an ESI Flex 5330, $355 \mathrm{~nm}$ UV Nd:YAG laser system was also employed. This system was similar, technically, to the 5200 model except that it offered the possibility of using either a Gaussian or tophat beam profile at the workpiece and it incorporated a Zoom Beam Expander to allow the beam spot size to be changed between $53 \mu \mathrm{m} \& 123 \mu \mathrm{m}$ at $2 \mu \mathrm{m}$ resolution. Figure 8 is an end view of a multimode polymer waveguide fabricated using the top-hat beam profile. From our study, qualitatively, there was no apparent improvement offered by the top-hat over the Gaussian beam profile, but this does not, in any way, conclude that the propagation loss would be the same for both, for which measurements need to be carried out.

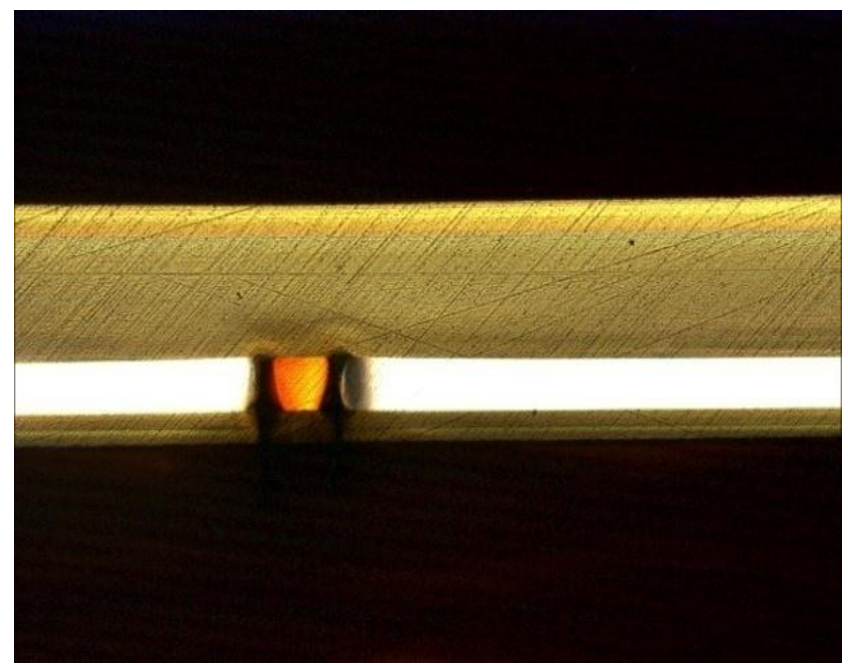

Figure 8: Optical microscope image of a cross-section through a Truemode polymer waveguide of $35 \mu \mathrm{m} \times 70 \mu \mathrm{m}$ ablated using the Flex 5330 model laser system with top hat beam profile.

\section{(C) Excimer Laser Ablation of Optical Waveguides}

The Excimer reported here is a 7000 Series Exitech Krypton Fluoride ( $\mathrm{KrF}$ ) laser operating at $248 \mathrm{~nm}$ wavelength with $20 \mathrm{~ns}$ pulse length. The system operates in both energy and voltage modes with values ranging from $0-250 \mathrm{~mJ} /$ pulse and $17-24 \mathrm{kV}$ respectively. The output energy can be manipulated by an attenuator controlled by Aerotech U500 software. The system has a CCD camera for viewing samples placed on an XYZ $\theta$ stage, with an aligner camera for focus setting. To define the size and shape of the beam spot at the workpiece the beam is passed through a mask which is then focussed at the sample through a changeable projection lens (currently $\mathrm{x} 10$ reduction, with $10.0 \mathrm{~J} / \mathrm{cm}^{2}$ achievable at the workpiece). This enables non-circular beam spots to be used simply by changing the shape of the mask.

For the purposes of direct ablative micromachining the most useful Excimer wavelengths are $248 \mathrm{~nm}(\mathrm{KrF})$ and $193 \mathrm{~nm}(\mathrm{ArF})$, the former is more widely used, especially in optical interconnection research such as those geared towards polymer waveguide fabrication, thought to very efficient with high etch rate [3]. The photon energies of $\mathrm{KrF}$ beam are in the right order of magnitude for various bonds associated with polymers making it a photochemically-dominated process with minimum HAZ; lately, pico- and femto-second ultra short pulse $\mathrm{KrF}$ lasers are now available to further reduce the HAZ.

Although other polymer materials have been investigated to demonstrate the photochemical clean nature of Excimer laser ablation, new materials still require the establishment of the correct process parameters for waveguide fabrications. The initial waveguide fabrication trial is shown in Figure 9 processed at a feed rate of $4.29 \mathrm{~mm} / \mathrm{min}$ and $25 \mathrm{~Hz}$ pulse repetition rate. Fig. 9a is a plan view of $300 \mu \mathrm{m}$ wide grooves machined to leave a $50 \mu \mathrm{m}$ multimode waveguide, while Fig. $9 \mathrm{~b}$ is a cross-section view of the waveguide with slightly tapered sidewalls for which work is underway to improve upon this. The author of [3] opined that the tapering can be reduced by increasing the number of shots at higher fluence of $\sim 2 \mathrm{~J} \mathrm{~cm}^{-2}$. Although the effects of these two parameters have been investigated, we cannot yet confirm how significant these factors are in relation to the tapering effect of the ablated profile. It was further observed, during our laser system characterization, that the laser focus position can also account for some of the tapering effect.

The flexibility offered by Excimer lasers and their mask projection features make them indispensable tools for integrated mirror fabrications, and is the core of research on this type of laser. Work is in progress aimed at defining low loss metallised and non-metallised 2D \& 3D mirrors for inplane and out-of-plane coupling respectively.
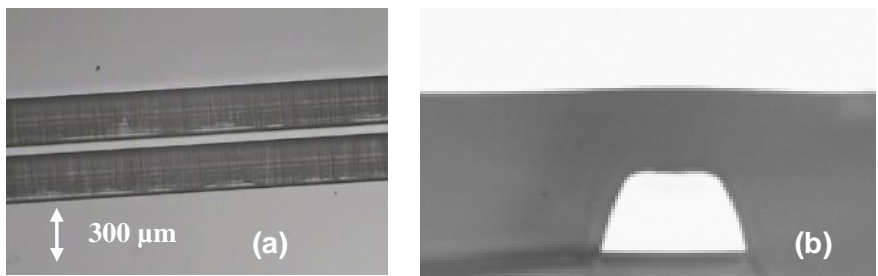

Figure 9: Excimer laser ablation of waveguides. (a) An optical microscope image showing the top view of a single multimode waveguide, (b) Cross-section of a $50 \mu \mathrm{m}$ x $35 \mu \mathrm{m}$ multimode waveguide.

\section{Summary and Conclusions}


Laser ablation of optical polymer waveguide materials using three different lasers, namely $248 \mathrm{~nm}$ Excimer, $355 \mathrm{~nm}$ UV Nd:YAG and $10.6 \mu \mathrm{m} \mathrm{CO}_{2}$ has been demonstrated. The use of $\mathrm{CO}_{2}$ for this purpose is reported, for the first time, at the point of writing. The $\mathrm{CO}_{2}$ laser machining process is purely photothermal, but can machine at very high rates. On the other hand, the Excimer laser can machine finer features, but at a slower rate with a largely photochemical process. The $355 \mathrm{~nm}$ UV Nd:YAG laser ablation is thought to be a combination of photothermal and photochemical mechanisms, both acting to a different degree depending on the experimental parameters used. At this stage, the waveguides have largely been detected using backlighting only and work is underway to measure their loss characteristics. The demonstration of the use of these three laser systems for the fabrication of waveguide structures may provide a route for the rapid deployment of this technology into the targeted industry as many of these systems are already used in PCB manufacturing facilities.

\section{Acknowledgments}

The research is part of the OPCB-Flagship project, financially supported by the UK Engineering and Physical Sciences Research Council through the Innovative Electronics Manufacturing Research Centre (I $e$ MRC). The authors would like to thank all collaborating companies in the OPCB project especially Exxelis and Dow Corning for providing the optical polymers used. Our thanks also go to Dr Karen Williams for her initial input in the project.

\section{References}

1. Chuang, W. C., Ho, C. T., and Shyu, R. F. A New Method to Fabricate Polymer Waveguides.

PROGRESS IN ELECTROMAGNETICS

RESEARCH SYMPOSIUM, 92-95 (2005).

2. Uhlig, S. ORMOCER Materials Characterization,

LAP - \& Micro-Processing - Applied to Optical Interconnects and High-Frequency Packaging. PhD Thesis (2006).

3. Bityurin, N. Studies on laser ablation of polymers, Annu. Rep. Prog. Chem., Sect. C: Phys. Chem., 2005, 101, 216- 247

4. Pfleging, W., et al Excimer Laser Material Processing - State Of The Art and New Approaches in Microsystem Technology.

5. Chen, Y., Naessens, K., Baets, R., Liao, Y. \& Tseng, A. Ablation of transparent materials using Excimer lasers for photonic applications. OPTICAL REVIEW 12, 427-441 (2005).

6. Harvey, E. C., Remnant, J. L., Rumsby, P. T. \& Gower, M. C. Microstructuring by Excimer laser. Proc SPIE Int Soc Opt Eng 2639, 266-277 (1995).

7. Naessens, K., Ottevaere, H., Van Daele, P. \& Baets, R. Flexible fabrication of microlenses in polymer layers with Excimer laser ablation. Appl. Surf. Sci. 208, 159-164 (2003).
8. Van Steenberge, G. et al. MT-compatible laserablated interconnections for optical printed circuit boards. J. Lightwave Technol. 22, 2083-90 (2004).

9. $\mathrm{Su}, \mathrm{K}$. et al., "Siloxane materials for optical applications," Proc. SPIE Vol. 6029, 60291C, ICO20: Materials and Nanostructures; Wei Lu, Jeff Young; Eds., Jan. 2006.

10. Colas, A., "silcones: preparation, properties and performance", Dow Corning, Life Sciences. Source: http://www.dowcorning.com/content/webabstract/AB S_01-3077.asp. [Accessed : September 2009]

11. Material Data Sheet [Accessed September 2008] : Available from :

http://www.exxelis.com/products/Truemodedatasheet-f.pdf

12. Van Steenberge, G. et al. Laser ablation of parallel optical interconnect waveguides. IEEE Photonics Technology Letters 18, 1106-1108 (2006

13. HENDRICKX, N ; VAN STEENBERGE, $\mathrm{G}$; GEERINCK, P ; VAN DAELE, P; Laser ablation as an enabling technology for the structuring of optical multilayer structures.; 8th International Conference on Laser Ablation (COLA'05) - 2005 p. 171-171

14. Enbutsu, K. et al. Multimode Optical Waveguide Fabricated by UV Cured Epoxy Resin for Optical Interconnection. APCC OECC -PROCEEDINGS-, 1648-1651 (1999).

15. Dangel, R. et al. Development of a low-cost low-loss polymer waveguide technology for parallel optical interconnect applications. (2004).

16. Illy, E. K., Piper, J. A., Brown, D. J. W. \& Withford, M. J. Enhanced polymer ablation rates using highrepetition-rate ultraviolet lasers. IEEE Journal on Selected Topics in Quantum Electronics 5, 15431548 (1999).

17. Chen, Y., Naessens, K., Baets, R., Liao, Y. \& Tseng, A. Ablation of transparent materials using Excimer lasers for photonic applications. OPTICAL REVIEW $12,427-441$ (2005).

18. Wei, M. -. \& Yang, H. Cumulative Heat Effect in Excimer Laser Ablation of Polymer PC and ABS. Int J Adv Manuf Technol 21, 1029-1034 (2003). 